\title{
Social Impact of Outreach at the Pierre Auger Observatory
}

\author{
Beatriz García $^{* a}$ for the Pierre Auger Collaboration ${ }^{\dagger b}$ \\ ${ }^{a}$ Instituto de Tecnologías en Detección y Astropartículas, Figueroa Alcorta 122, 5501 Godoy \\ Cruz, Mendoza, Argentina \\ ${ }^{b}$ Observatorio Pierre Auger, Av. San Martín Norte 304, 5613 Malargüe, Argentina \\ E-mail: auger_spokespersons@fnal.gov \\ Full author list: http://www.auger.org/archive/authors_icrc_2019.html
}

\begin{abstract}
The Pierre Auger Observatory in Argentina started its construction in 1999 and is operating at full capacity since 2008. From its initiation, scientists and staff of the Observatory are focused on working at the frontiers of scientific knowledge and on serving as a reference on education and outreach. The impact of the interactive new approach on science communication for the general public and the connections with other institutions in the region such as the Planetarium of Malargüe and the University of Cuyo produce great synergy with the community. The year 2019, the year of the centenary of the International Astronomical Union, provides an opportunity to develop new activities in the framework of continuous innovation in education and outreach. In this presentation, we propose a virtual trip through the 20 years that the Auger Observatory transmits scientific knowledge in Malargüe and beyond.
\end{abstract}

36th International Cosmic Ray Conference - ICRC2019

24 July - 1 August, 2019

Madison, Wisconsin, USA

\footnotetext{
* Speaker.

${ }^{\dagger}$ For collaboration list see PoS(ICRC2019)1177
} 


\section{Introduction}

The year 2019 marks the 20th anniversary of the formal inauguration of the Pierre Auger Observatory [1]. At this anniversary the scientists and staff of the Observatory are not only working with the well-known surface and fluorescence detectors, but they are also installing new detectors and instruments to complete AugerPrime, the upgrade of the Observatory. During this period of upgrading the Observatory, the challenges of education and communication with the public become more and more important and the methods by which this task can be fulfilled demand ever more creativity. During this new stage of the Observatory, it is appropriate to look at its achievements as a guideline to face the challenges for the future.

\section{Pierre Auger Observatory and the Community}

Since the first meeting of the incipient Pierre Auger Collaboration in Valle Grande, San Rafael in 1996, where the project leaders Jim Cronin, Alan Watson, and Paul Mantsch were present (Figure 1, left), the Observatory meetings became opportunities to share various projects with the community, to establish lasting relationships and to participate in local activities. Examples of such actions are the organization of Science Fairs, participation in the parade celebrating the anniversary of Malarguie and the activities at the Visitor Center, which includes visits from schools originating from the whole country, and of tourists from all over the world. This important task was led from the beginning by Greg Snow (Figure 1, right), who passed away on May 4, 2019, and to whom we dedicate this work.

An example of a positive effect of the Observatory on the local community is the contribution of several members of the Auger collaboration as professors in the Faculty of Exact and Natural Sciences of the Universidad Nacional de Cuyo in the Malargüe Annex. Many university students have performed internships at the Observatory, including students of local secondary technical schools, which resulted in the hiring of three electromechanical technicians who were incorporated into two new Auger projects. Members of the Observatory participated in global actions, such as GalileoMobile [2], which included the installation of a small telescope at the school in the town of Carapacho in 2015 (see Figure 2).

The Observatory staff is in continuous contact with both the city and the countryside due to the travel of technicians maintaining the detectors. Families that have detectors in their fields and the schools in the site consider the loan of batteries for power storage very important. The laying of power lines in very remote areas, required to feed the fluorescence telescopes, had resulting benefits for the local inhabitants near those facilities. In 2005, a study on the social impact of the Observatory was carried out. The study was based on new concepts on organizational management through Corporate Social Responsibility criteria. Social Impact is defined as the "change or set of lasting changes that occur in society, economy, science, technology and the environment, improving their indicators as a result of the execution of research, development, innovation, that introduce added value to products, services, processes and technologies". The social impact is not only about the result, but it relates to its effect, the impact on people, the economy, and the environment. The full set of results at that moment exceeds the scope of this article, but from the study it was concluded that the relationship between the Observatory and the government was present since the genesis of 

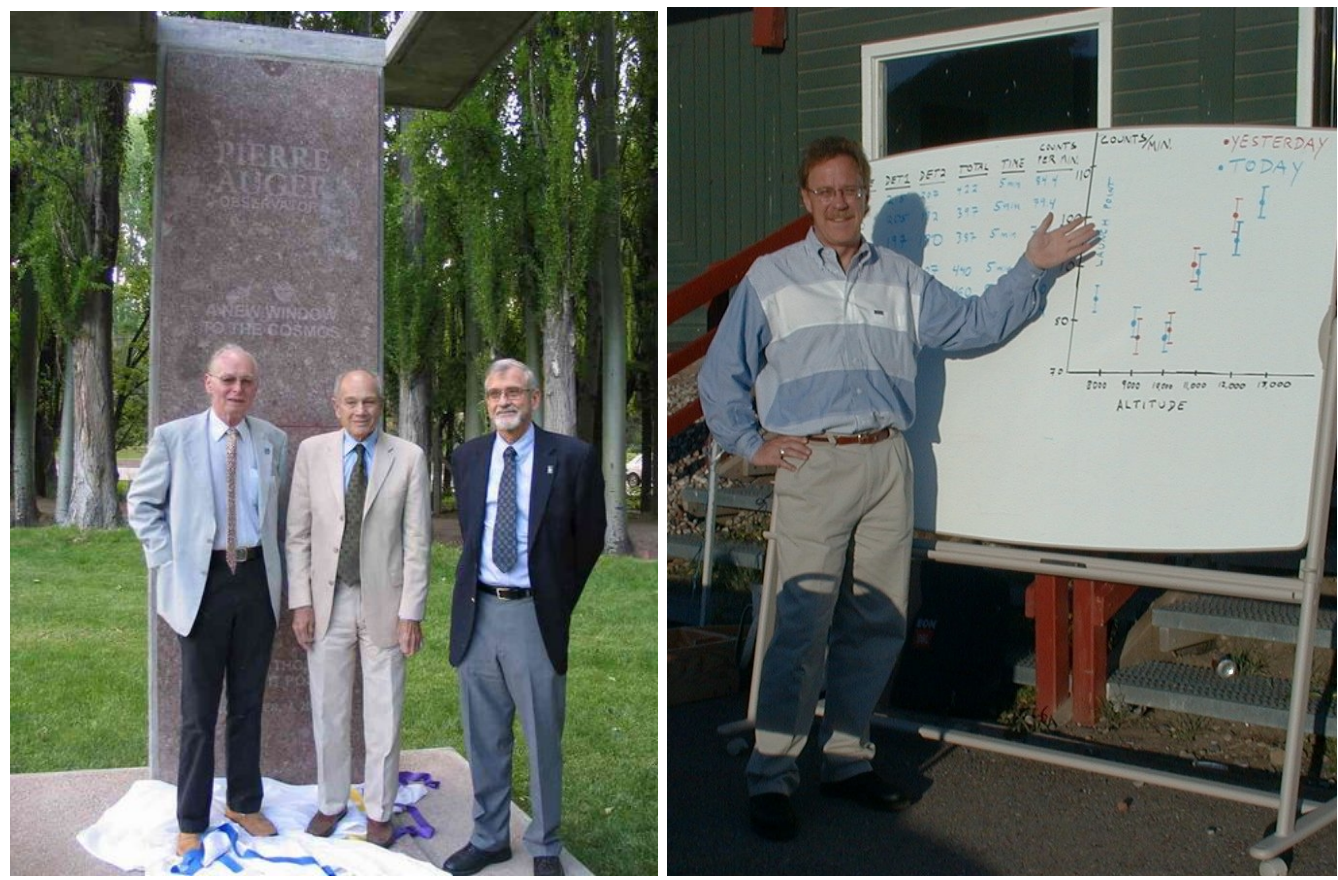

Figure 1: First directors and manager of the Observatory. From left to right: Alan Watson, Jim Cronin and Paul Mantsch (left); Greg Snow happily explaining data to the crowd at a balloon launch site. Red data points are from a test flight from the previous day on the 90th anniversary of the discovery of Cosmic Rays (right).

the project, as it was largely the decision and vision of the local authorities that finally managed to get the Observatory installed there. When analyzing the actions carried out by the Observatory staff in Malargüe, it was noticed that the Observatory staff work in a network with local companies and government. Examples of this network are concrete actions for the community, such as:

- The Michigan scholarships, whose purpose is the stay of a high-school student at Michigan University during a year. This is made possible thanks to the coordinated work of the $\mathrm{Mu}$ nicipal government, the Municipal Academy of English, schools in the area, the National Technological University and the Observatory.

- The construction of the High School "Cronin" using funds from the Granger Foundation.

- The construction of the Malargüe Planetarium, financed by the Municipality, with the advice from scientists from the Observatory.

- The dissemination of free guided visits to the Observatory, working together with the local government, the Malarguie Tourism office, and tourist agencies.

\subsection{The Visitor Center}

The Visitor Center (VC) of the Observatory was conceived as part of the complete design of the central building of the Observatory (see Figure 3), which is a landmark in the city. It was installed thanks to a contribution of the University of Chicago, and designed by the architects 


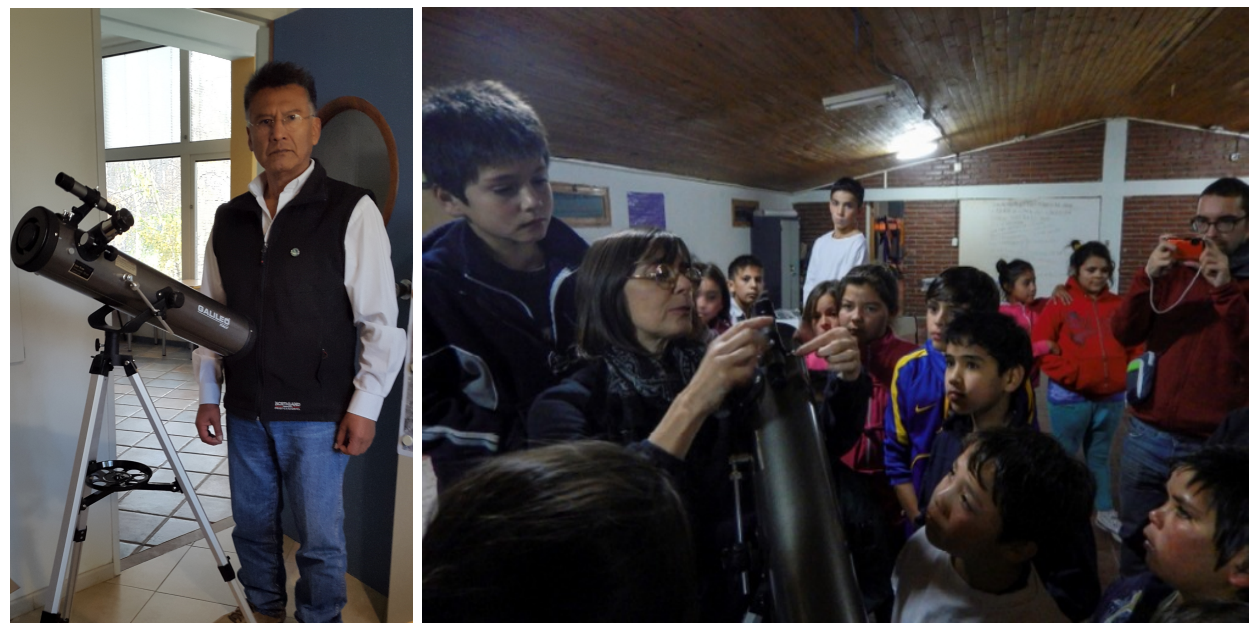

Figure 2: GalileoMobile Project. Telescope at the office of the Site Manager Gualberto Ávila (left); assembling the telescope at the school in Carapacho (right).

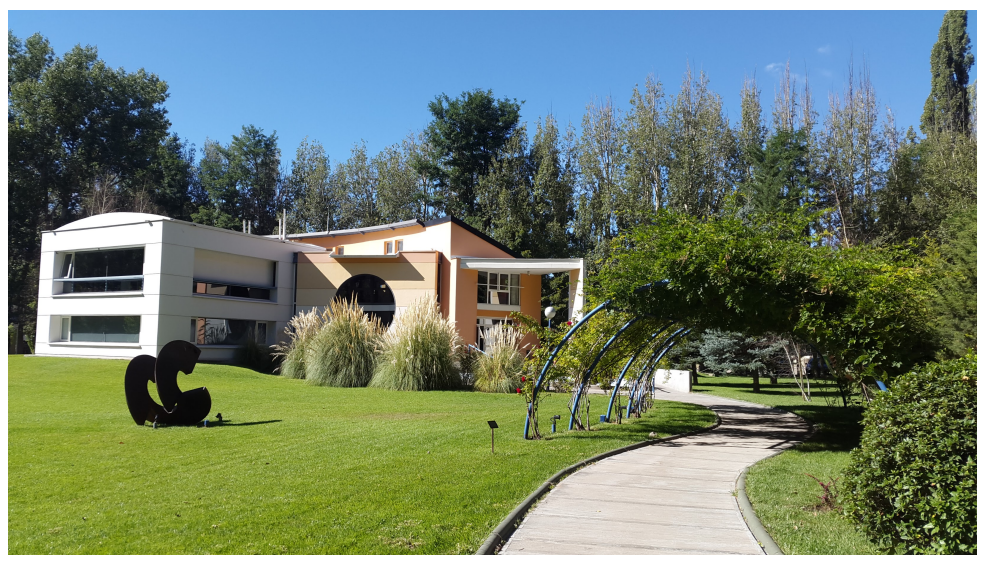

Figure 3: The Pierre Auger Observatory heaquarters in Malargüe.

Boccanegra and Paoletti. During the first years, visitors were received at the main area of the VC where an explanatory talk on the Observatory and its objectives were given by trained guides, ready to answer questions related to the nature of the cosmic rays: what are they? from where do they come from? how do they arrive with such energy?

Several special presentations were designed to explain the scientific and engineering issues related to the Observatory. Throughout the years, the contact with the public has evolved. Hand in hand with the International Year of Physics (2005), the International Year of Astronomy (2009), the International Year of Light (2015) and having passed the centenary year of the discovery of cosmic rays by Victor Hess in 1912, we decided to address the public in a more creative way, appealing to interactivity and new applications to make the VC more attractive. By applying the principles of Design Thinking [3], the VC was completely remodeled in 2017. This change also meant a revitalization of resources and led to an increase in the number of visitors and the possibility of reaching a wider audience, taking into account methods of inclusive science, based on adaptations for blind and visually impaired, deaf and disabled persons and also through new tools, as virtual 

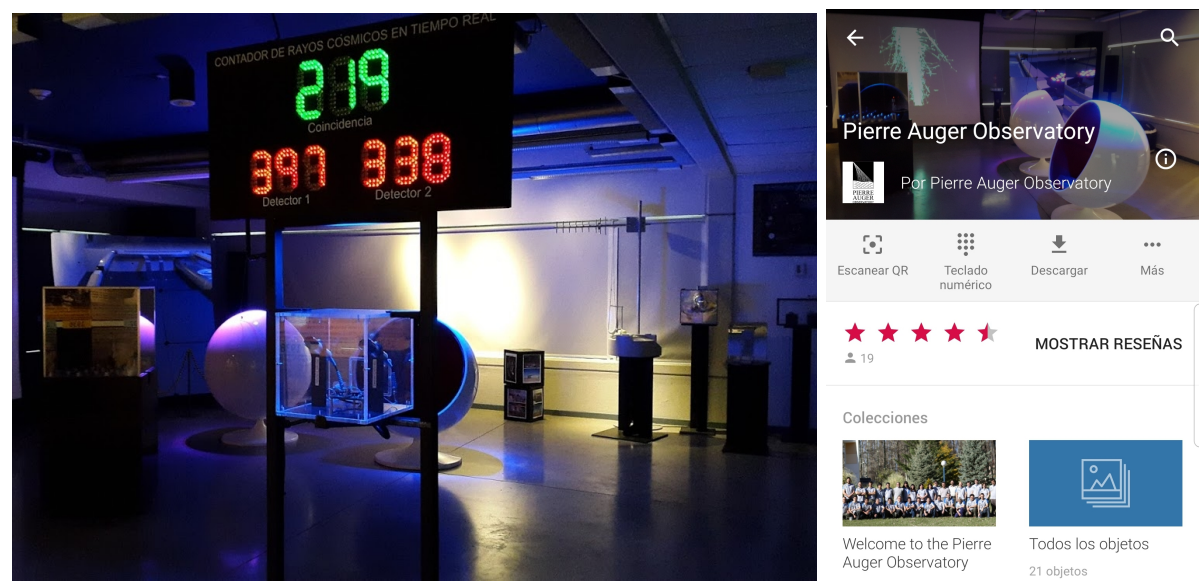

Figure 4: Visitor Center: general view (left), virtual tour (right).
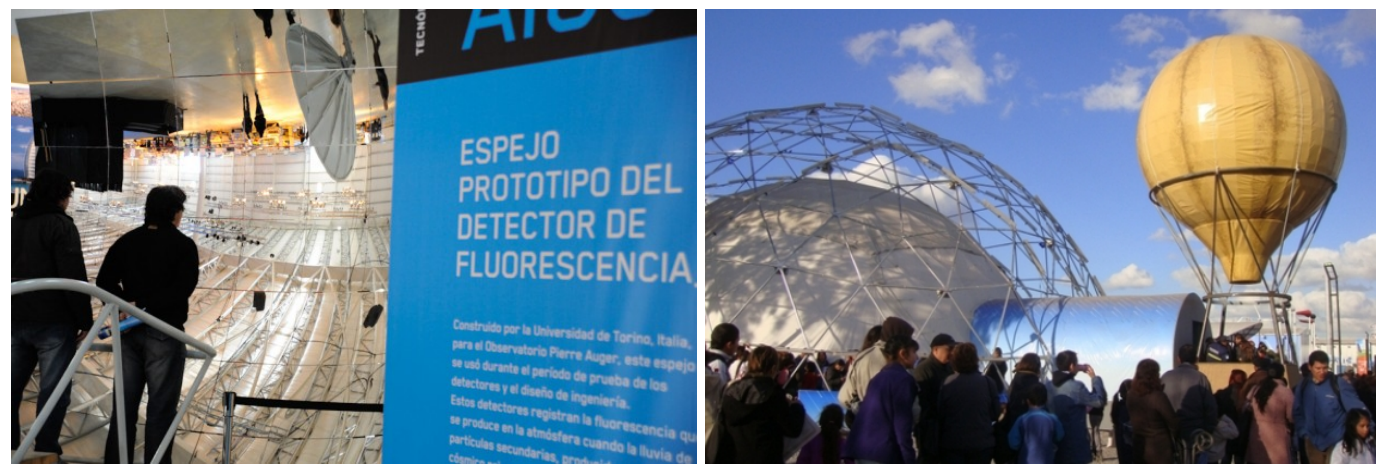

Figure 5: Auger in: Tecnópolis 2011 [4] (left), Tecnópolis 2012 (right).

guides (see Figure 4).

Since 2002, the Pierre Auger Observatory has received more than 123,000 visitors, and at the public exhibitions as Tecnópolis [4], the mega-exhibition of science, technology, industry and art in Argentina supported by the Ministry of Science, Technology and Productive Innovation between 2011 and 2016 (see Figure 5), the Auger space received more than 3 million visitors.

\subsection{The Science Fair}

Since 2005, the Observatory organizes bi-annual Science Fairs aiming to provide a space for students to promote research skills. The main objective of this activity is to guide and stimulate young people in the use of the scientific method by promoting a scientific exchange between the exhibitors, and establish communication between the students and the researchers of the Pierre Auger Observatory.

In the last editions, the Fairs received visitors from all over the country. With the possibility to show projects developed in the schools to observatory scientists, a special bond is created between participants and jury (made up of members of the collaboration). Over the years, a significant improvement in the quality of the proposals has encouraged us to continue with the initiative [5]. 
In 2019, a new approach to this activity was proposed to the Collaboration Board of the Observatory, that takes into account a series of anniversaries and events taking place in 2019: the 20th anniversary of the Observatory, the 100 years of the International Astronomical Union (www.iau100.org), the 50 years of the first moon landing, the International Year of the Periodic Table of the Chemical Elements and a Total Solar Eclipse, that crosses the Argentinean territory on July 2nd. Taking these events as flagships, we aim for the Auger 2019 Science Fair to address specific issues and to create a stronger appeal to the community.

\subsection{The Parade}

Since the year 2001, the Pierre Auger Collaboration participates in the parade celebrating the anniversary of the department of Malargüe [5]. Along with children from schools, non-profit organizations, dance groups and musicians, the scientists working at the Observatory parade and participate in the joy and being part of the community. Without a doubt, they have contributed to the changes of the Malargüe community throughout the 20 years of existence of the Observatory.

\subsection{Public access to the scientific data}

The Pierre Auger Collaboration agreed to make $10 \%$ of their data available to the public. The website of the Comisión Nacional de Energía Atómica (CNEA) allows browsing the events compiled since 2004, and it is updated daily [6]. This resource permits to enter a selection for events in an "event search window", search for an event with the selection menu or show an event that is already in cache. It is also possible to download ASCII files with all events for further analysis. In some cases, the available data have been used for the development of university-level degree projects and projects of middle-level students.

\section{Pierre Auger and the Scientific Tourism}

Malargüe is an attractive city for scientific tourism. The nearby presence of the Andes mountain range contains ski slopes and other activities linked to mountaineering. The existence of caverns (Caverna de las Brujas in Bardas Blancas), wetlands (Llancanelo lagoon, the largest bird reserve in the country), paleontological records and unique volcanic areas (Payunia), as well as the possibility of dark skies, contribute to the intrinsic value of the department in a remarkable way. In this context, the installation of the Malargüe Planetarium, founded in 2008 and dependent on the Municipality [7], was one of the many contributions by the Observatory in science communication. The cooperation between the Observatory and the Planetarium led to the production of two of the first Argentinean shows for digital planetaria, "Cosmic Rays"(for the centenary of their discovery) and Travelers of the Light (on the occasion of the International Year of Light, IYL2015). In the latter case, the show was conceived as part of a trans-media production, which includes educational material for teachers, short videos designed for use in schools, exclusive interviews, among other special products. The cooperation with the Planetarium has also ensured the installation of interactive modules in the Planetarium Museum (Figure 6). 


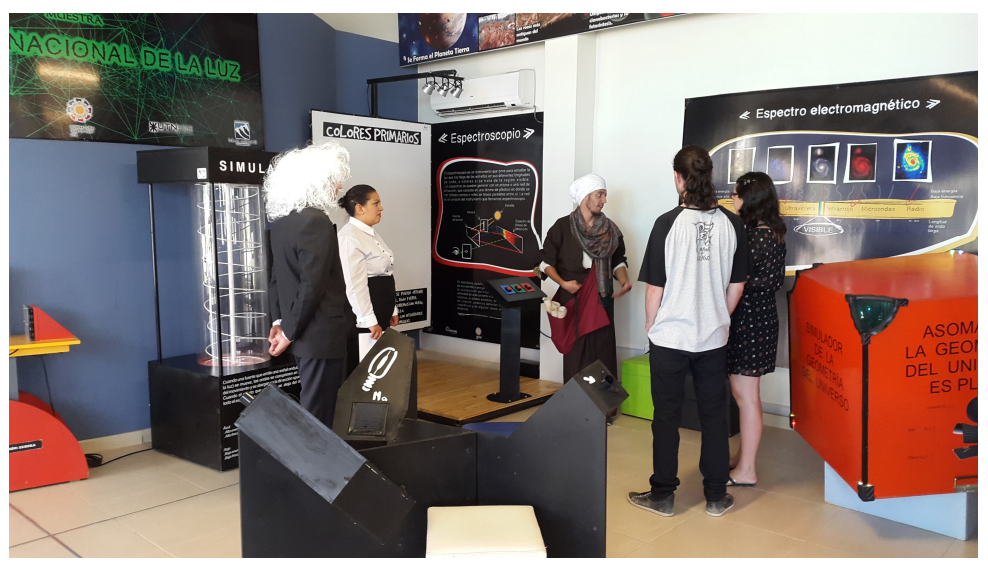

Figure 6: Interactive Museum at Planetario Malargüe, IYL2015 space.

\section{Conclusions and next steps}

The Pierre Auger Observatory is strong in the community, in terms of education and the dissemination of the physical and astronomical sciences. After 20 years of existence in the Department of Malarguie, it is time to update the impact studies, analyze the efficiency of the knowledge transfer to the community and to improve the synergy between the different actors in the local society. It is possible, on the other hand, to observe how Malargüe as a result of Auger is integrated into the world by adhering to scientific activities that care for and preserve the environment and at the same time educate the local community, for example in very important and actual topics for astronomical observations such as the control of the Light Pollution. It should be noted that this activity has great adhesion in the community that benefits from the high level of visibility and acceptance that the observatory generates. The new forms of communication allow us to establish a direct relationship with the public through social networks. It is imperative that the Observatory improves the use of these new trends as they generate a large visibility and impact. The collaboration moves forward with a strategic campaign using social networks, the preparation of a package of released data plus the procedure to manage them to be disseminated massively, and the production of contents for interactive screens. A fluid contact with the press and the institutions interested in the subject of astroparticle physics is essential and, in the particular case of the Pierre Auger Observatory itself, an inter-institutional network between those scientific centers that are part of the International Collaboration will be part of the outreach effort for the next decade. This network enables the extensive use of different resources in education and dissemination in a coordinated manner, with a broad spectrum of ideas, proposals and projects and interaction between scientists and interested people, throughout the world.

\section{References}

[1] Pierre Auger Observatory, http://www.auger.org

[2] GalileoMobile, http://www.constellationproject.org/

[3] Pérez, S. Maya, J. Mancilla, A., De la Vega, G., Yelos, D, Cancio, A. García, B., Think on Science and innovate with design, Proceedings of CAP Conference, Fukuoka, Japan, pp 204-205, 2018.

https://drive.google.com/file/d/1JqGgsFvxZlATxvoCZ-kGo4xVjTxBQS7Q/view?usp=sharing 
[4] Tecnópolis 2011, http://www.tecnopolis.mincyt.gob.ar/categoria/2011/page/2/

[5] Timmermans, C. for the Pierre Auger Collaboration, Education and public outreach of the Pierre Auger Observatory, Proceedings of the ICRC2017, Busan, Korea, PoS(ICRC2017)392, https://pos.sissa.it/301/392/pdf

[6] Public Event Display at Pierre Auger Observatory, https://www.auger.org/index.php/edu-outreach/event-display

[7] Planetario Malargüe, https://planetario.malargue.gov.ar/institucional/ 